\title{
Chemical and Morphological Changes in an Arsenopyrite Crystal Induced by Thiobacillus ferrooxidans
}

\author{
M. A. Makita,* A. Duarte, ,** S. Arévalo*** and E. Orrantia** \\ * Instituto Tecnológico de Chihuahua II, Chihuahua, Chih. México 31109 \\ ** Centro de Investigación en Materiales Avanzados, Chihuahua, Chih. México 31109 \\ *** Universidad Autónoma de Chihuahua, Chihuahua, Chih. México 31109
}

Thiobacillus ferrooxidans is a chemolitothrophic, acidophilic, and aerobic bacteria which catalyses the oxidation of inorganic substrates; in particular mineral sulfides. It is widely used in bio-leaching of commercial interest ores.[1]. In despite the mechanism(s) for the oxidation of mineral sulfides catalyzed by Thiobacillus ferrooxidans is not completely understood, three mechanisms, for this process, have been described. (i) the direct mechanism whereby bacteria attach to the mineral surface and dissolve the mineral species, (ii) the indirect mechanism where the bacteria catalyses the regeneration of the leaching ferric ion, and (iii) the electrochemical route where the bacteria attach to the noblest mineral and galvanically protect the mineral from dissolution thus enhancing the oxidation of the less noble mineral(s)[2].

Scanning electron microscopy has been used to study the oxidation of the mineral surface and to investigate patterns caused by bacterial attachment in pyrite, arsenopyrite, chalcopyrite, molybdenite and covellite crystals both synthetic and natural. In this study we show that an arsenic-resistant Thiobacillus ferrooxidans wild type strain, modifies the crystal lattice of an arsenopyrite crystal, and provokes "corrosion pores" or "oxidation holes", if we compare figure 1a, where no exists a bioleaching treatment, with figures $1 \mathrm{~b}, 1 \mathrm{c}$, and $1 \mathrm{~d}$, in these cases crystalline structure is lost, and finally (figure 1d), the mineral is disaggregated in thin particles, this mechanism permit the recovery of valuable metals as gold, copper and zinc. Table 1 shows the analysis elemental, the arsenic of the arsenopyrite is enough to inhibit the bacterial growth, however T. ferrooxidans resist this concentration and it is capable to have metabolic activity.

The use of scanning electron microscopy, in the present work, has shown how the surface of an arsenopyrite crystal, contained in a lead ore, is oxidized by the addition of an arsenic-resistant wild type $T$. ferrooxidans strain, obtained from acid mine drainage. Therefore we can to conclude that a bio-leaching treatment is a good alternative for the treatment of refractory ores. when the bacteria is capable to generate oxidation holes.

\section{References}

[1] S. R. Hutchins et al., Annu. Rev. Microbiol. 40 (1986) 311

[2] N. Rowson and A. Saeid. Mine \& Quarry. 26 (2), (1997) 35

[3] M. I. Sampson et al., Minerals Engineering, Vol. 13, No. 6, (2000) 643

[4] Financial support: CONACYT-DAIC 34223-B, CONACYT-FOSIVILLA 20000405002 


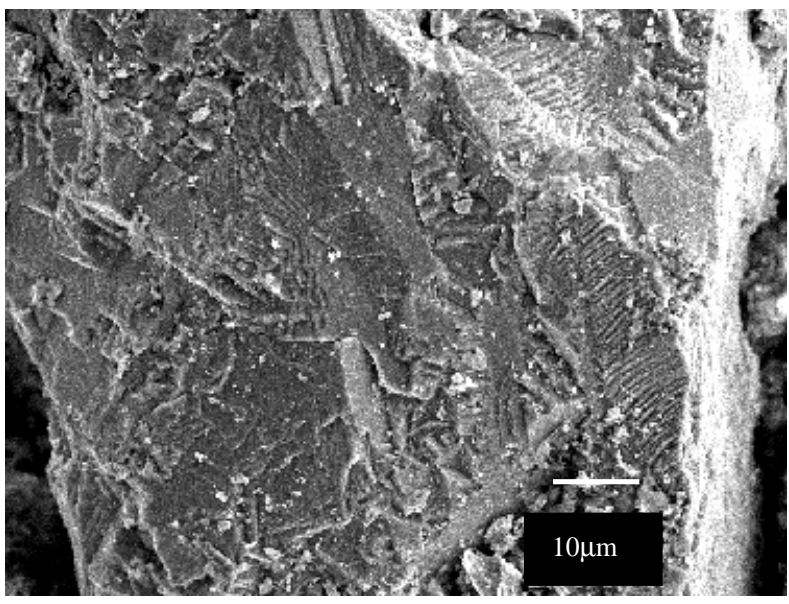

Figure 1a

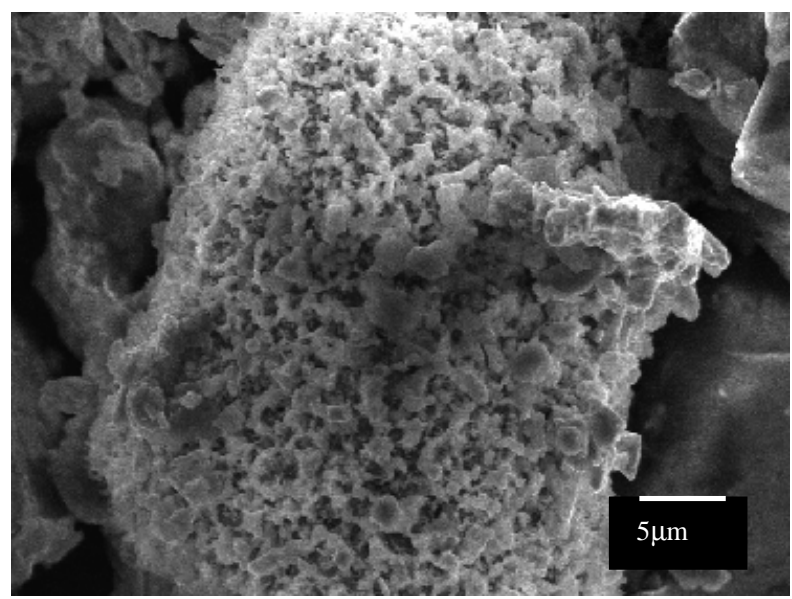

Figure 1c

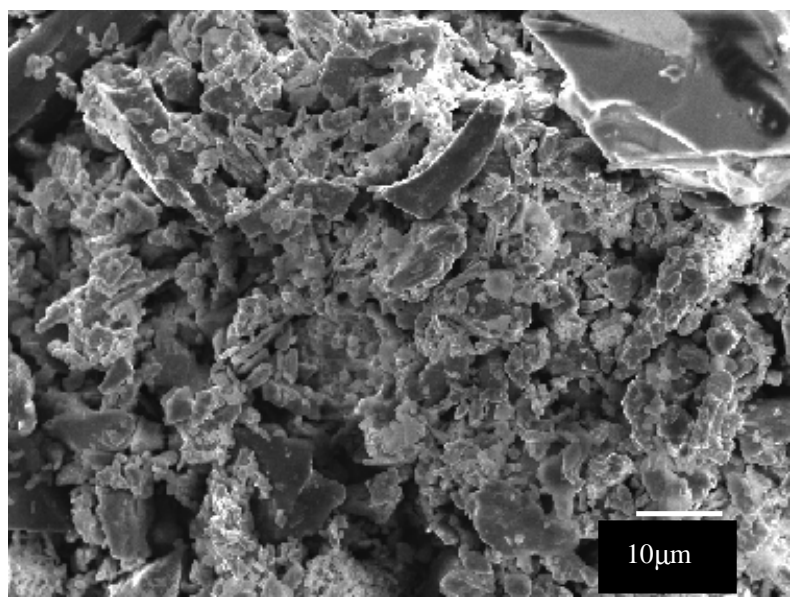

Figure $1 b$

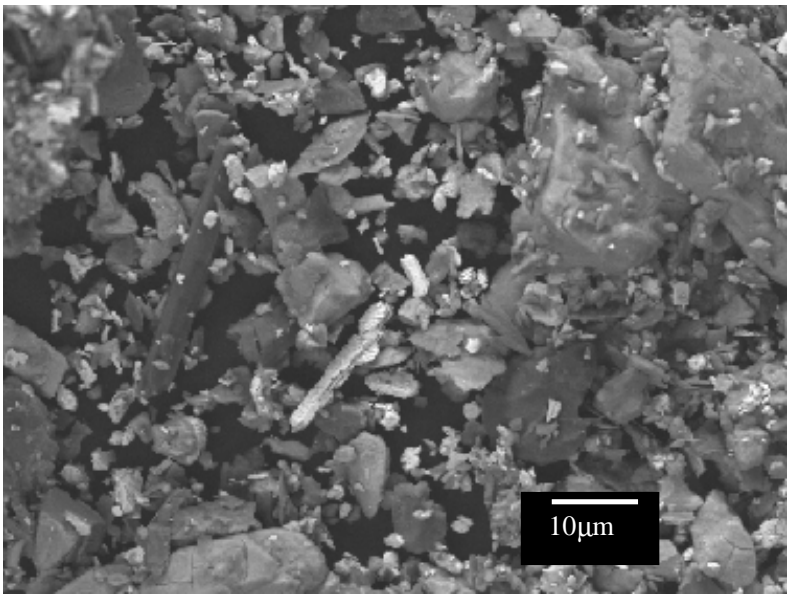

Figure 1d

Figure 1. 1a shows non bio-leached mineral, $1 \mathrm{~b}$ and 1c show the bio-oxidation effect after 39 days and $1 \mathrm{~d}$ the bio-oxidation effect after 64 days.

Table 1. Ore Chemical Composition

\begin{tabular}{|c|c|}
\hline Element & \% Weight \\
\hline Arsenic & 21.78 \\
\hline Iron & 21.13 \\
\hline Sulfur & 12.02 \\
\hline Lead & 9.66 \\
\hline Zinc & 9.42 \\
\hline
\end{tabular}

